\title{
ANÁLISE AMBIENTAL DO USO E VULNERABILIDADE DO SOLO COM SISTEMAS DE INFORMAÇÕES GEOGRÁFICAS.
}

Olívia Aparecida Rodolfo Figueiredo ${ }^{1}$, Valter Antonio Becegato ${ }^{1}$, Manoael Marques Maciel ${ }^{2}$, João Batista Pereira Cabral ${ }^{3}$ (1 - Professor (a) da Universidade do Estado de Santa CatarinaUDESC-Lages-SC, E-mail: a2oaf@cav.udesc.br; becegato@cav.udesc.br; 2 - Observatório

Nacional-ON, E-mail: marques@on.br; 3 - Professor do Departamento de Geografia da Universidade Federal de Goiás-Campus de Jataí-GO, E-mail:jbcabral2000@yahoo.com.br)

\section{Resumo}

Grande atenção tem sido dada ao uso e a necessidade de planejamento ambiental integrando a estimativa de desempenho (aptidão), manejo e sua relação com o potencial de erosão para o desenvolvimento de um manejo sustentável. O presente estudo objetivou a aplicação da Equação Universal de Perdas de Solos (USLE), em ambiente de sistemas de informações geográficas e sua comparação com aptidão agrícola. Foi avaliado para cada unidade de mapeamento os índices de estimativa de perdas de solos (A) para diversos fatores CPgenéricos e EPmédios versus a indicação sugerida pela FAO/Brasileiro. Observou-se que os índices de estimativa da erosão potencial restringiram mais a utilização da terra para agricultura do que pela aptidão agrícola.

Palavras chave: SIG, uso do solo, perdas de solo

\section{Abstract \\ ENVIRONMENTAL ANALYSIS OF THE USE AND VULNERABILITY OF THE SOIL WITH GEOGRAPHIC INFORMATION SYSTEM}

A great attention has been dedicate to soil use and the necessity of environmental planning integrating the performance estimation ("Land Suitability"), manipulation and its relationship with the erosion potential to the development of a sustainable manipulation. The present study objectives the application of Universal Soil Loss Equation (USLE) with Geographic Information System. It were evaluate, for each map unity, the estimate index of soil loses (A) to several factors of $\mathrm{CP}$ generic and EP medium versus FAO/Brazilian System suggested indication. It was observed that the estimate index of potential erosion, were more restrict to the agricultural soil use than to Land Suitability.

Key words: GIS, soil use, soil loss. 


\section{1 - Introdução}

Grande atenção tem sido dada ao uso do solo e a suas implicações econômicas, sociais e ambientais. A crescente demanda de alimentos em razão do crescimento demográfico leva a utilização cada vez mais intensiva do solo. Considerando que a curto prazo o solo é um recurso natural não renovável, ele precisa ser utilizado de forma sustentável para que este recurso não se esgote nas gerações futuras. Recomenda-se que antes de qualquer ação dentro de uma área, é necessário classificá-la de acordo com sua capacidade de uso e indicar as práticas necessárias para um bom manejo de solo.

Conforme Ramalho Filho e Beek (1995), a avaliação das classes de aptidão agrícola é feita mediante o estudo comparativo entre os graus de limitação e os valores estipulados conforme a região em estudo. Assim, a classe de aptidão agrícola é obtida em função do grau limitativo mais forte. Observa-se que o fator de suscetibilidade a erosão os graus de limitação são determinados em função das classes de declive (S).

Para o Iapar (1977), a forma e intensidade da erosão hídrica, embora estejam relacionadas com atributos intrínsecos do solo, são mais influenciadas pelos efeitos das precipitações pluviais, a natureza do solo, o relevo, a vegetação, e a ação do homem, havendo uma interação de todos estes fatores.

A ação da chuva no fenômeno erosão fundamenta-se em três características das precipitações pluviais: intensidade (temporal); quantidade (limite de absorção do solo); e freqüência ou distribuição (época do ano). A natureza do solo é um dos fatores que exerce maior influência no volume de enxurrada, quantidade de terra e elementos nutrientes arrastados pela erosão, caracterizados pela infiltração da água, dispersão e transporte das partículas, dependendo principalmente das características físicas como: textura, estrutura e drenagem interna do perfil do solo.

O relevo é um dos fatores principais relacionado com a erosão hídrica, pois em terrenos planos praticamente a degradação não se manifesta. A medida que o relevo deixa de ser plano dois aspectos condicionam a erosão: a declividade (S) e o comprimento de rampa ( L ). Quanto mais inclinado for um terreno, maior será sua suscetibilidade á erosão, pois aumentando a velocidade da água de enxurrada, maior será o arraste de partículas do solo.

O efeito do comprimento da pendente está em função do aumento da velocidade da água de enxurrada, á mediada que aumenta seu percurso numa superfície inclinada. Assim, quanto maior o comprimento da rampa maior a massa d'água, cujo aumento imprime ainda 
mais velocidade à água, aumentando as perdas de terra por unidade de área. Segundo a Embrapa (1980), as pesquisas determinam um índice numérico que representa os fatores de declividade e comprimento de rampa.

A integração de tais conhecimentos: aptidão agrícola, manejo e sua relação com potencial de erosão do solo, são de extrema importância para o processo no qual se possa definir o tipo de uso do solo, que não está necessariamente relacionado com a sua produtividade.

Os Sistemas de informações geográficas vem se tornando com freqüência um forte aliado nas pesquisas de estudos ambientais, como por exemplo, (Lopes Assad, 1995; Rodrigues et al, 2001 e Becegato et al., 2004). O objetivo do presente trabalho foi determinar o fator topográfico (LS), da Equação Universal de Perdas de Solo (USLE) em ambiente de SIG e aplicá-lo na avaliação da suscetibilidade à erosão em diferentes tipos solos.

\section{2 - Material e Métodos}

\section{1 - Caracterização da área}

Situada no primeiro Planalto Paranaense (Figura 1), a aproximadamente $30 \mathrm{Km}$ de Curitiba e delimitada pelas coordenadas UTMs 663500 a 675000 m. E e 7152800 a 7163600 m. S do meridiano central $-51^{\circ}$. A porção Sudoeste do Primeiro Planalto Paranaense está representada litologicamente por migmatitos e gnaisses granitizados do complexo cristalino Maack (1953), rochas associadas aos migmatitos como xistos magnesianos, anfibolitos, quartzitos e diques de rocha básica, ortogonal a retangular. Vasta rede de drenagem permeia a área (Figura 2).

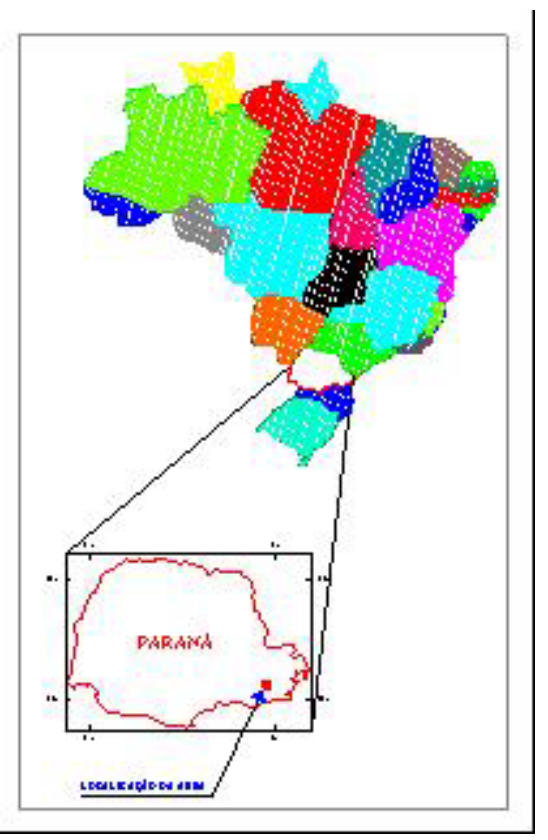

Figura 1. Localização da área de estudos. 


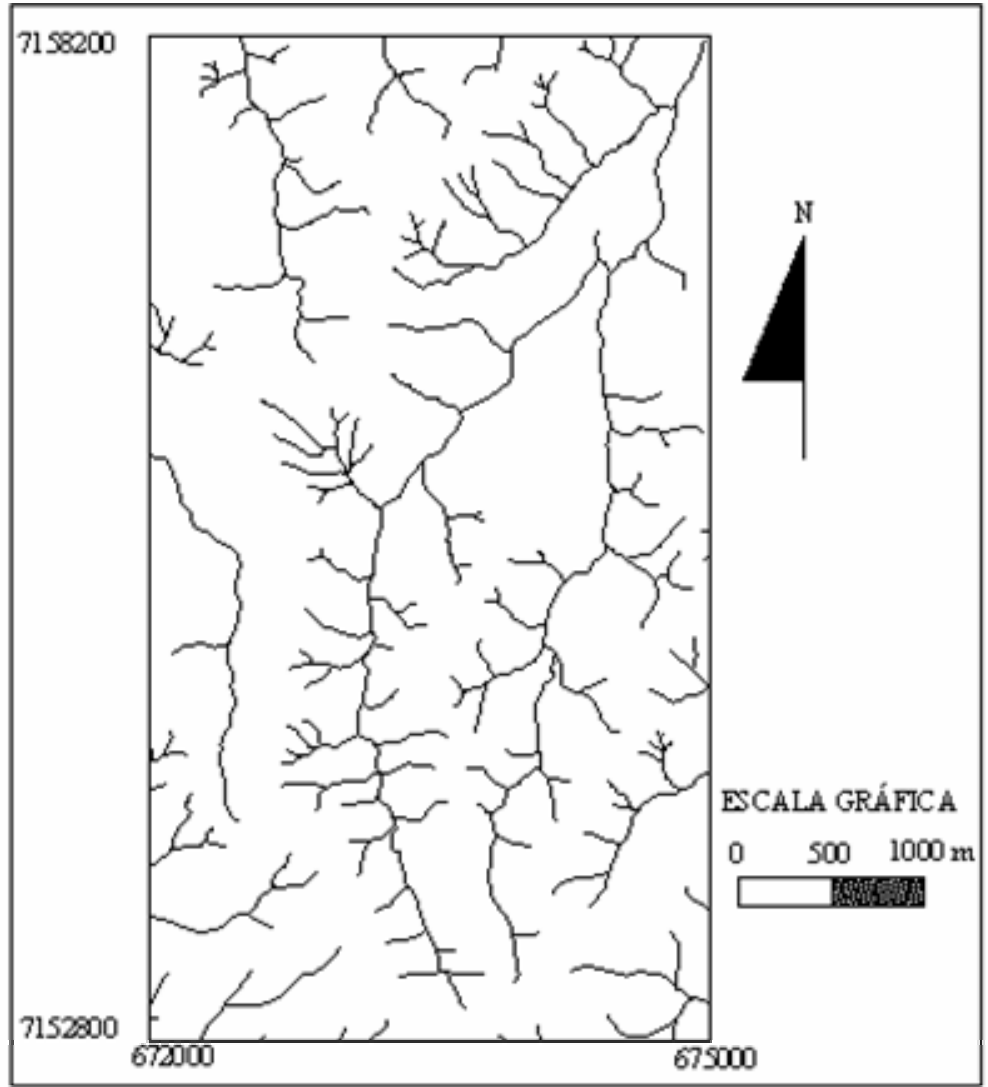

Figura 2. Rede de drenagem

\section{2 - Procedimentos metodológicos}

A primeira etapa antes da interpretação propriamente dita, foi a de delimitar a área útil ou efetiva de cada fotografia segundo metodologia descrita por Rabben (1960) e confeccionar overlays. Sobre as fotografias aéreas através da formação do estereopar, foi realizada a interpretação do uso, traçando-se sobre os overlays independentes as classes do uso da terra com base nos elementos convencionais de reconhecimento como a tonalidade, textura, forma, arranjo espacial, tamanho, padrão altura dos indivíduos, convergência de evidência, segundo Moraes (1968) e Ray (1963), além do apoio de campo.

A distribuição espacial do uso e manejo do solo foi determinada através da interpretação de fotografias aéreas, cujo vôo foi realizado no ano 1996. Foram consideradas as seguintes classes temáticas: Agricultura, mata ciliar, mata alta e campo. Foi definida uma escala média das fotografias conforme orientações de Ricci \& Petri (1965).

A erosividade da chuva ou fator $\mathrm{R}$ foi estimada a partir do mapa de isoerodentes desenvolvido por Rufino et al., (1993), correspondendo ao valor interpolado de $5.625 \mathrm{Mj} \mathrm{mm}$ 


\section{GEOAMBIENTE ON-LINE}

Revista Eletrônica do Curso de Geografia do Campus Jataí - UFG www.jatai.ufg.br/geo/geoambiente

GEO

Jataí-GO | n.7 | jul-dez/2006 |

$\mathrm{ha}^{-1} \mathrm{~h}^{-1} \mathrm{ano}^{-1}$. O índice de erosividade $\mathrm{EI}_{30}$ foi calculado pela expressão sugerida por Castro Filho et al., (1982), e convertido para o Sistema Internacional de Unidades Foster et al., (1981). Os dados obtidos são resultantes do registro das chuvas de 1972 a 1989 em trinta e uma estações da rede meteorológica do Instituto Agronômico do Paraná, e de pluviômetros de 144 postos, com período de recorrência de 25 a 100 anos, da rede meteorológica da Secretaria de Recursos Hídricos e Meio Ambiente do Paraná.

Para a estimativa da erodibilidade do solo (fator K), foram utilizados os índices propostos por Bertoni et al., (1975), com valores de 0,033 e 0,022 t.ha.ha ${ }^{-1} \cdot \mathrm{mm}^{-1}$ obtidos para os horizontes superficiais do Argisssolo Vermelho-Amarelo, Latossolo Vermelho-Amarelo, respectivamente. Para a classe dos Cambissolos, o valor de $\mathrm{K}$ foi de 0,0269 t.ha ha.ha ${ }^{-1} \cdot \mathrm{mm}^{-1}$ utilizado dos dados analíticos de Silva (1993), determinado pela equação de Roloff e Denardin (1994).

Os fatores comprimento de rampa (L) e declividade (S) que constituem em conjunto o fator topográfico foram calculados utilizando-se os seguintes procedimentos: A declividade representando o fator $\mathrm{S}$, extraído após a geração do modelo numérico do terreno (MNT), oriundo de arquivo digital contendo dados altimétricos de cartas topográficas escala 1:10.000 com curvas de níveis eqüidistantes de 5 metros interpoladas Figura 3.

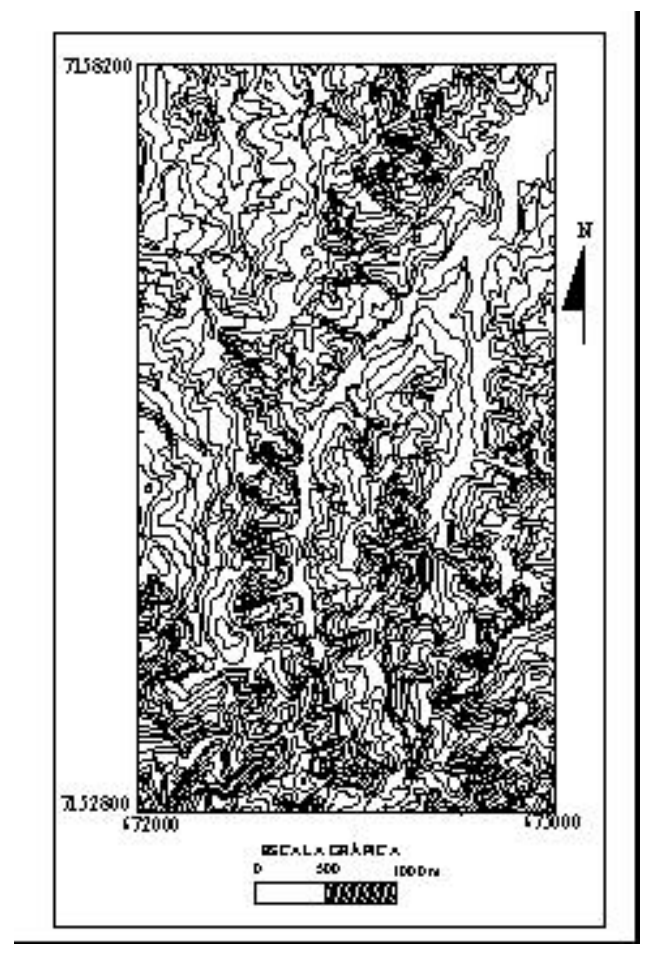

Figura 3. Curvas de níveis eqüidistantes 5 metros 


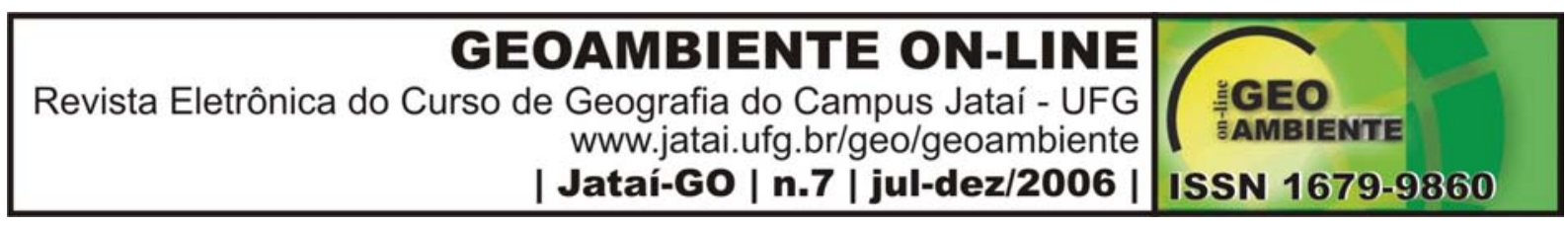

Tal arquivo foi transformato no formato raster, cujas imagens foram reclassificadas em intervalos de declividades: $0-3 \%, 3-8 \%, 8-12 \%, 12 \%-20 \%, 20 \%-45 \%$ e $>45 \%$, cujas classes foram propostas por Embrapa (1984). A determinação do comprimento de rampa (L) foi obtido conforme fluxograma (Figura 4). Para as faixas de rampa seguiu-se a metodologia baseada em Rocha et al., (1995), sendo que a imagem foi reclassificada em oito intervalos iguais, tendo cada intervalo $45^{\circ}$ totalizando $360^{\circ}$. Realizou-se tabulação cruzada das imagens reclassificadas, seguida de um agrupamento de pixels representativo do mesmo grupo de rampa. Foi extraído desse agrupamento de pixel faixas de valores das diferenças de alturas e ângulos médios das rampas com o respectivo valor do seno. Sabendo-se que $\mathrm{L}=$ DH/SENângulo, executou-se a divisão entre as imagens, gerando-se outras com os respectivos comprimentos de rampas. Para o cálculo do LS, utilizou-se a fórmula de Bertoni e Lombardi (1985): $\mathrm{LS}=0,00984 \mathrm{C}^{0,63} \mathrm{D}^{1,18}$ onde C é o comprimento da rampa em metros e $\mathrm{D}$ o grau do declive em porcentagem.

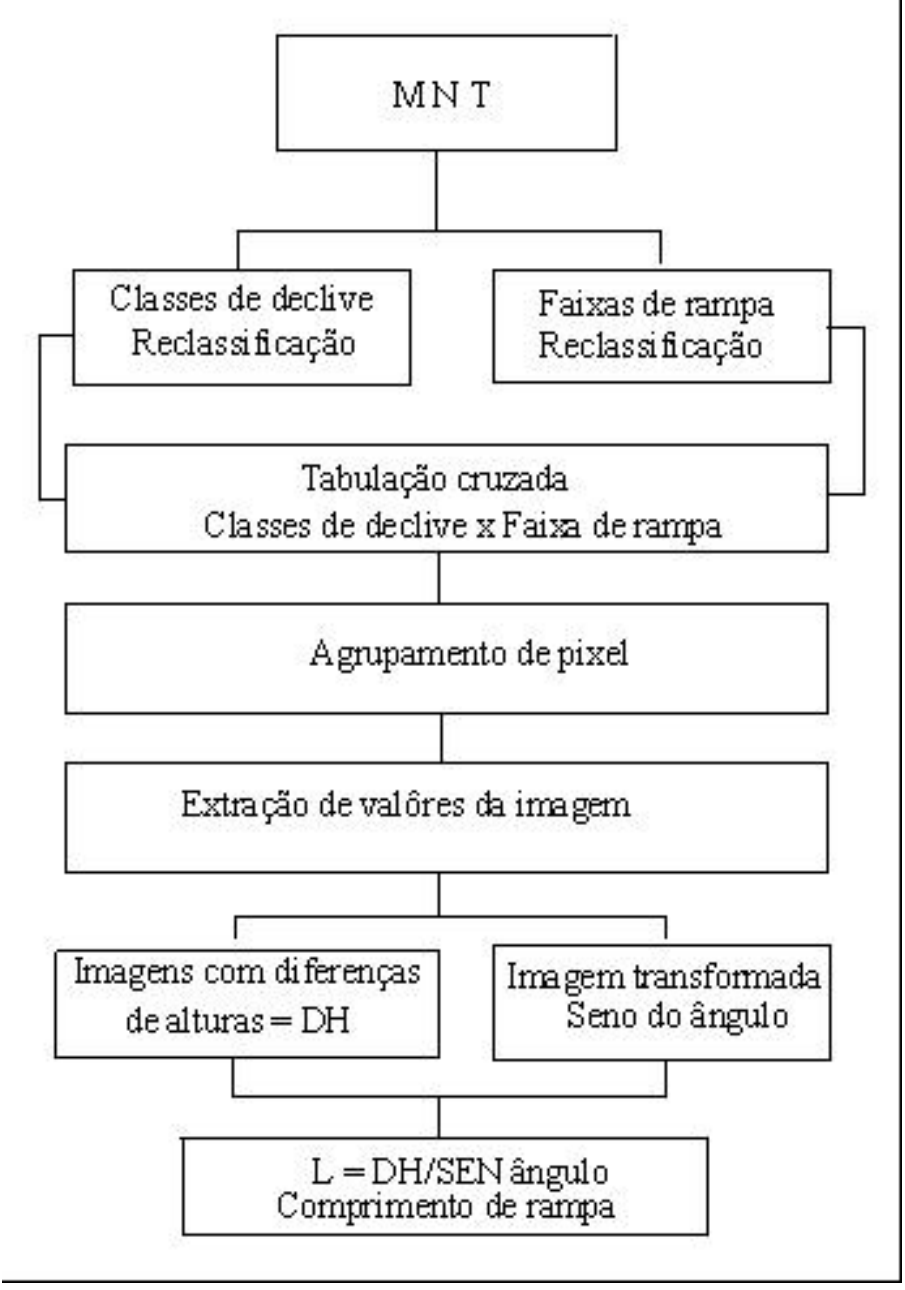

Figura 4 - Fluxograma para obtencão do fator (L). 


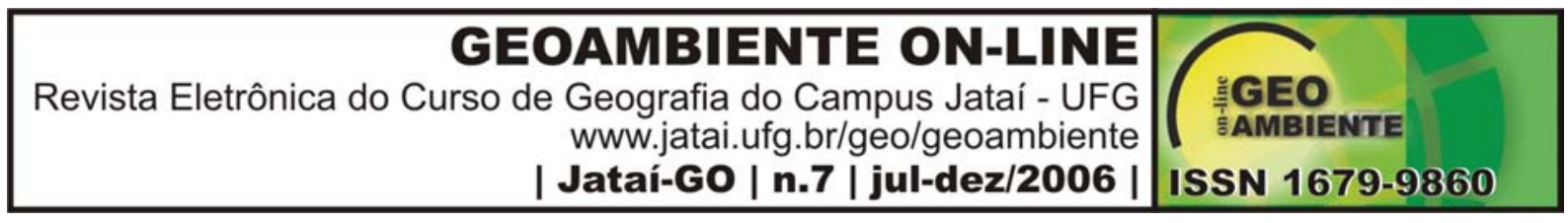

Por se tratar de dois fatores que mantém estreita relação, foi trabalhado conjuntamente, cujos índices utilizados (Tabela 1), foram definidos por Stein et al., (1987).

Tabela 1. Valores dos fatores CP para as classes de uso do solo

\begin{tabular}{ll}
\hline Classes de uso do solo & Valores de CP \\
\hline Agricultura & 0,20 \\
Campo nativo & 0,010 \\
Reflorestamento & 0,0001 \\
Pastagem & 0,10 \\
Floresta & 0,00004 \\
\hline
\end{tabular}

\section{3 - Resultados e Discussão}

De acordo com a Figura 5, observam-se quatro classes de uso dos solos e os respectivos percentuais de ocupação das mesmas estão expressas na Tabela 2. A área total possui 1.620 hectares, cuja classe predominante é o campo nativo com $38,74 \%$ e a menor mata com $30,49 \%$.

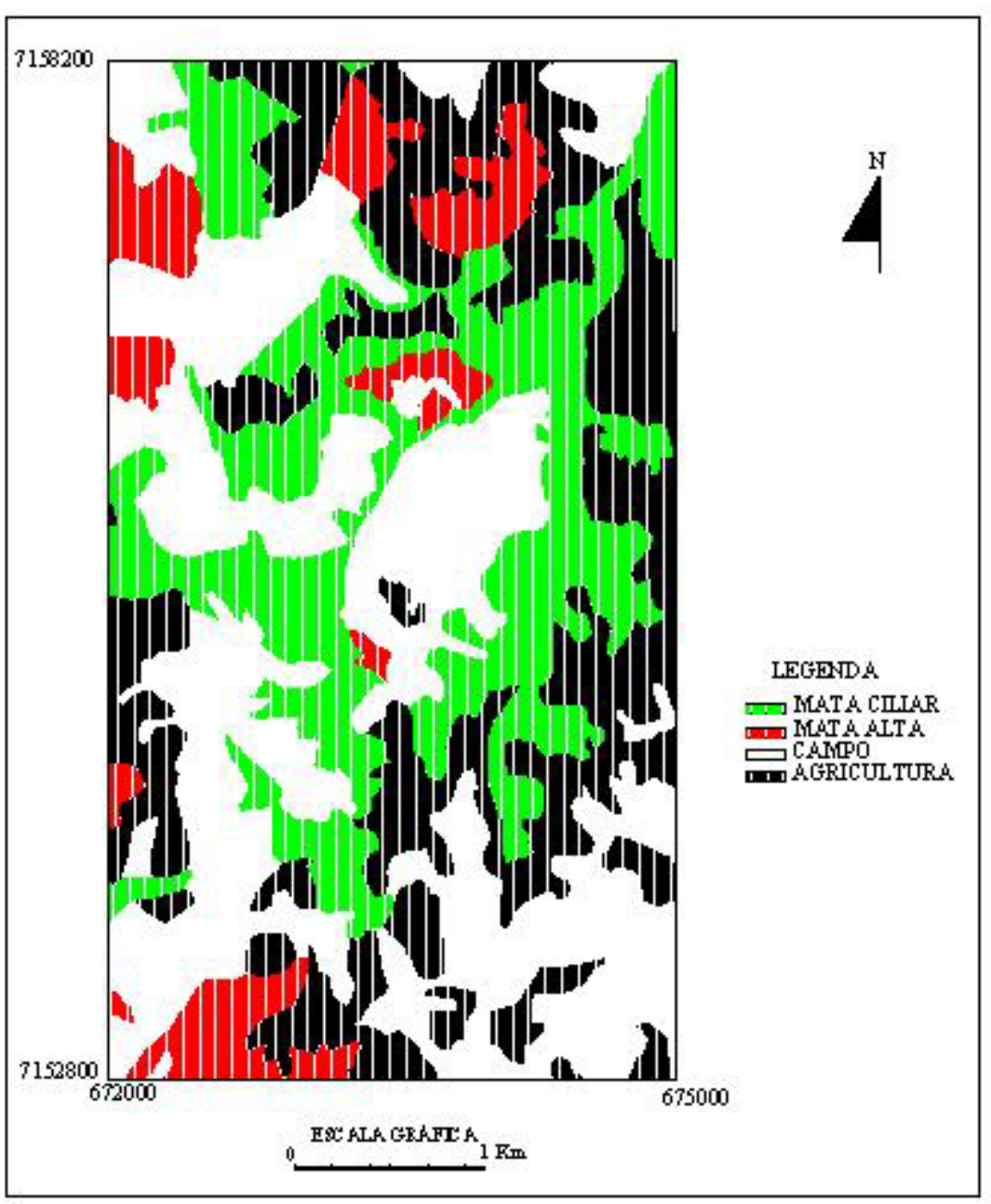

Figura 5. Mapa de uso e ocupação dos solos. 


\begin{tabular}{|c|c|}
\hline $\begin{array}{r}\text { GEOAMBIENTE ON-LINE } \\
\text { Revista Eletrônica do Curso de Geografia do Campus Jataí - UFG } \\
\text { www.jatai.ufg.br/geo/geoambiente } \\
\text { | Jatai-GO | n.7 | jul-dez/2006 | }\end{array}$ & $\begin{array}{l}\text { (ISGEO } \\
\text { ISSN } 1679-9860\end{array}$ \\
\hline
\end{tabular}

Tabela 2 - Classes de uso e ocupação do solo

\begin{tabular}{ccc}
\hline Classes de uso & \multicolumn{3}{c}{ Área } \\
\cline { 2 - 3 } Mata & (ha) & $(\%)$ \\
Mata ciliar & 122,51 & 7,56 \\
Agricultura & 371,43 & 22,93 \\
Campo & 498,52 & 30,77 \\
Total & 627,54 & 38,74 \\
\hline
\end{tabular}

As distribuições espaciais dos cinco tipos de solos estão amostrados na Figura 6, cuja predominância é pelos Argissolos com $82,35 \%$ e o menor pelo Cambissolo com $6,62 \%$. Na Tabela 3 encontram-se os valores de erodibilidade (fator K).

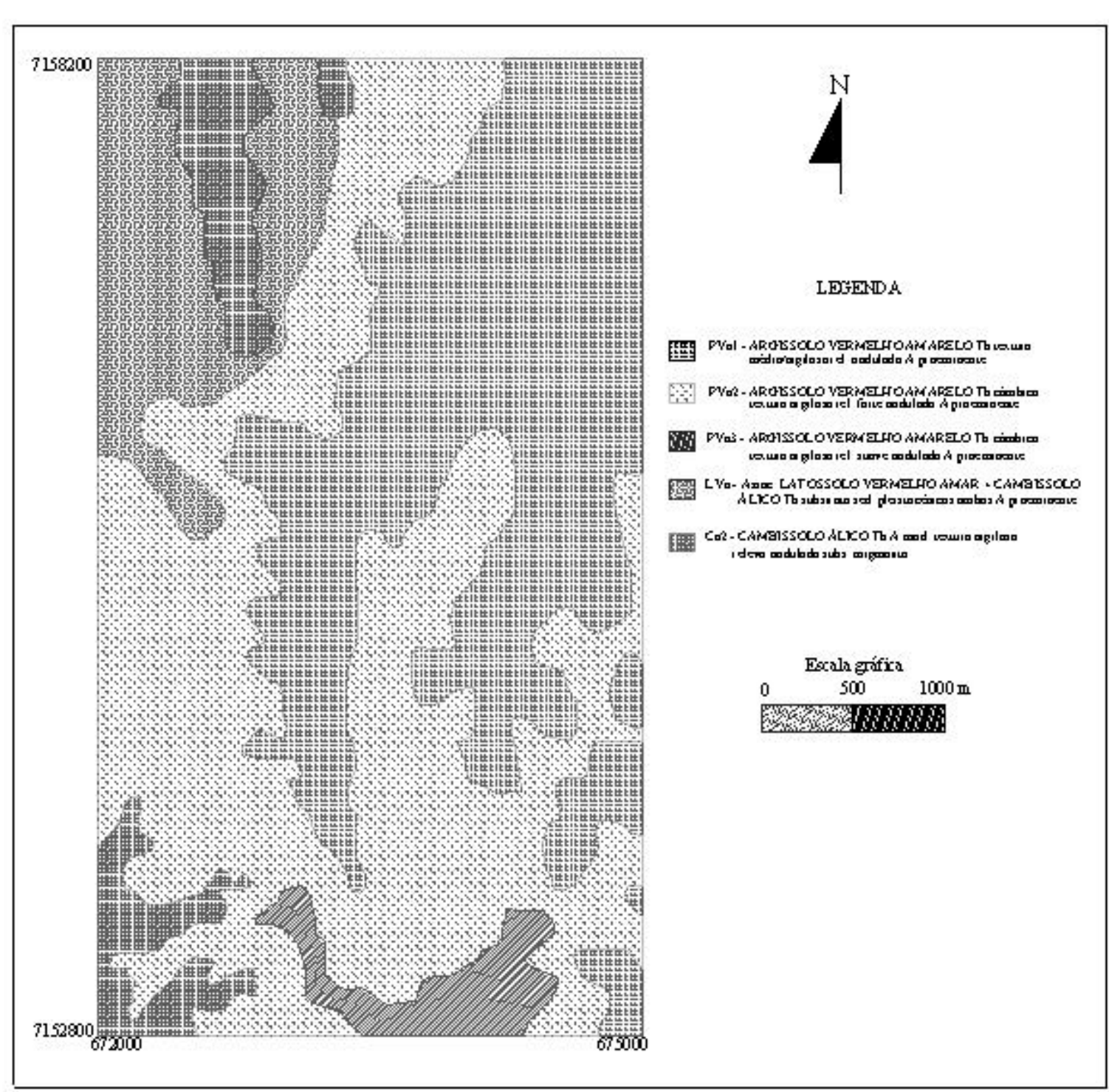

Figura 6. Mapa de solos. 
Tabela 3 - Unidades de mapeamento e valores de K.

Solos

Argissolo Vermelho-Amarelo-relevo forte ondulado-Pva2

Argissolo Vermelho-Amarelo-relevo ondulado-Pva1

Argissolo Vermelho-Amarelo-relevo suave ondulado-Pva3

Latossolo Vermelho-Amarelo-relevo suave ondulado-Lva

Cambissolo Alico-relevo ondulado-Ca2

Total

\begin{tabular}{ccc} 
& \multicolumn{2}{l}{ Área } \\
\cline { 2 - 3 } $\mathrm{K}^{*}$ & ha & $\%$ \\
--------- & ---- \\
0,033 & 702,90 & 43,38 \\
0,033 & 577,89 & 35,67 \\
0,033 & 53,46 & $3, .30$ \\
0,022 & 178,65 & 11,03 \\
0,026 & 107,10 & 6,62 \\
& 1.620 & 100 \\
\hline
\end{tabular}

$\left(^{*}\right)=$ t.ha.ha.ha ${ }^{-1} \cdot \mathrm{mm}^{-1}$

A classificação da aptidão agrícola das unidades de mapeamento foi baseada nos trabalhos do Ministério da Agricultura - Secretaria Nacional de Planejamento Agrícola (1981).

Tendo-se definido as classes de uso do solo discriminadas por unidade de mapeamento (Tabela 4), o próximo passo foi o cálculo da erosão potencial. Os valores dos índices de erosão potencial são resultantes do produto dos fatores R.K.LS da Equação Universal de Perdas de Solo. Correspondem às estimativas de perdas de solo em áreas continuamente destituídas de cobertura vegetal e sem qualquer intervenção antrópica. Os valores alcançados foram ordenados qualitativamente em cinco níveis: I - baixa (0-300 t.ha ${ }^{-1}$.ano $\left.{ }^{-1}\right)$; II - média (300-600 t.ha ${ }^{-1}$. ano $\left.^{-1}\right)$; III - alta (600-900 t.ha ${ }^{-1}$.ano $\left.{ }^{-1}\right)$; IV - muito alta (900-1200 t.ha ${ }^{-1}$.ano $\left.{ }^{-1}\right)$ e V - extremamente alta $\left(1200\right.$ - 8898 t.ha $^{-1} \cdot$ ano $\left.^{-1}\right)$. Esta classificação foi feita a partir dos histogramas dos valores contidos para todas as unidades de mapeamento. Utilizando-se os valores médios da erosão potencial (EP), quantificados por unidade de mapeamento, cruzouse com as áreas das classes de uso da terra.

Tabela 4 - Aptidão agrícola dos solos

Solos

Argissolo Vermelho Amarelo relevo ondulado - Pva1 Argissolo Vermelho Amarelo relevo forte ondulado - Pva2 Argissolo Vermelho Amarelo relevo suave ondulado - Pva3

Latossolo Vermelho Amarelo relevo ondulado - Lva Cambissolo Alico relevo ondulado - $\mathrm{Ca} 2$ Total

\begin{tabular}{|c|c|c|}
\hline \multirow{2}{*}{$\begin{array}{ll}\text { Classes } & \text { de } \\
\text { aptidão } & \end{array}$} & \multicolumn{2}{|l|}{ Área } \\
\hline & ha & $(\%)$ \\
\hline $2 " \mathrm{~b}(\mathrm{c})$ & 702,90 & 43,38 \\
\hline $4 \mathrm{p}$ & 577,89 & 35,67 \\
\hline $2 \mathrm{bc}$ & 53,46 & 3,30 \\
\hline $2 "$ (b) c & 178,65 & 11,03 \\
\hline 3 (b) & 107,10 & 6,62 \\
\hline & 1.620 & 100 \\
\hline
\end{tabular}




\section{GEOAMBIENTE ON-LINE}

Revista Eletrônica do Curso de Geografia do Campus Jataí - UFG www.jatai.ufg.br/geo/geoambiente

| Jataí-GO | n.7 | jul-dez/2006 |

Após a obtenção dos valores de EPmédia e CPgenéricos, calculou-se o índice de perdas de solos (A) por unidade de mapeamento, enquadrando por faixas de erosão potencial e a área da classe de uso correspondente. Desta forma foi possível visualizar as perdas e destacar com sombreamento as áreas incompatíveis com os índices de limite de tolerância de perdas de solos.

Na Tabela 5 referente a unidade de mapeamento Ca2 nível de aptidão 3(b), cujo uso do solo é permitido para agricultura restrita no nível B onde ocorre a seguinte distribuição de uso de solo: mata alta, mata de várzea, agricultura e campo nativo, para as faixas de erosão potencial, totalizando de 107,1 ha. As estimativas de erosão potencial das classes muito alta e extremamente alta, representam $69,9 \%$ da área total da unidade de mapeamento Ca2. O ideal seria que as classes de uso com os maiores valores de CP ocupassem as áreas com os menores valores de EP e vice-versa, como as áreas da classe de uso com matas, onde as perdas estão dentro de um limite tolerável, possibilitando uma amplitude no grau de limitação em relação à EP.

Tabela 5 - Distribuição do uso atual do solo por faixas de erosão potencial da unidade de mapeamento $\mathrm{Ca} 2$.

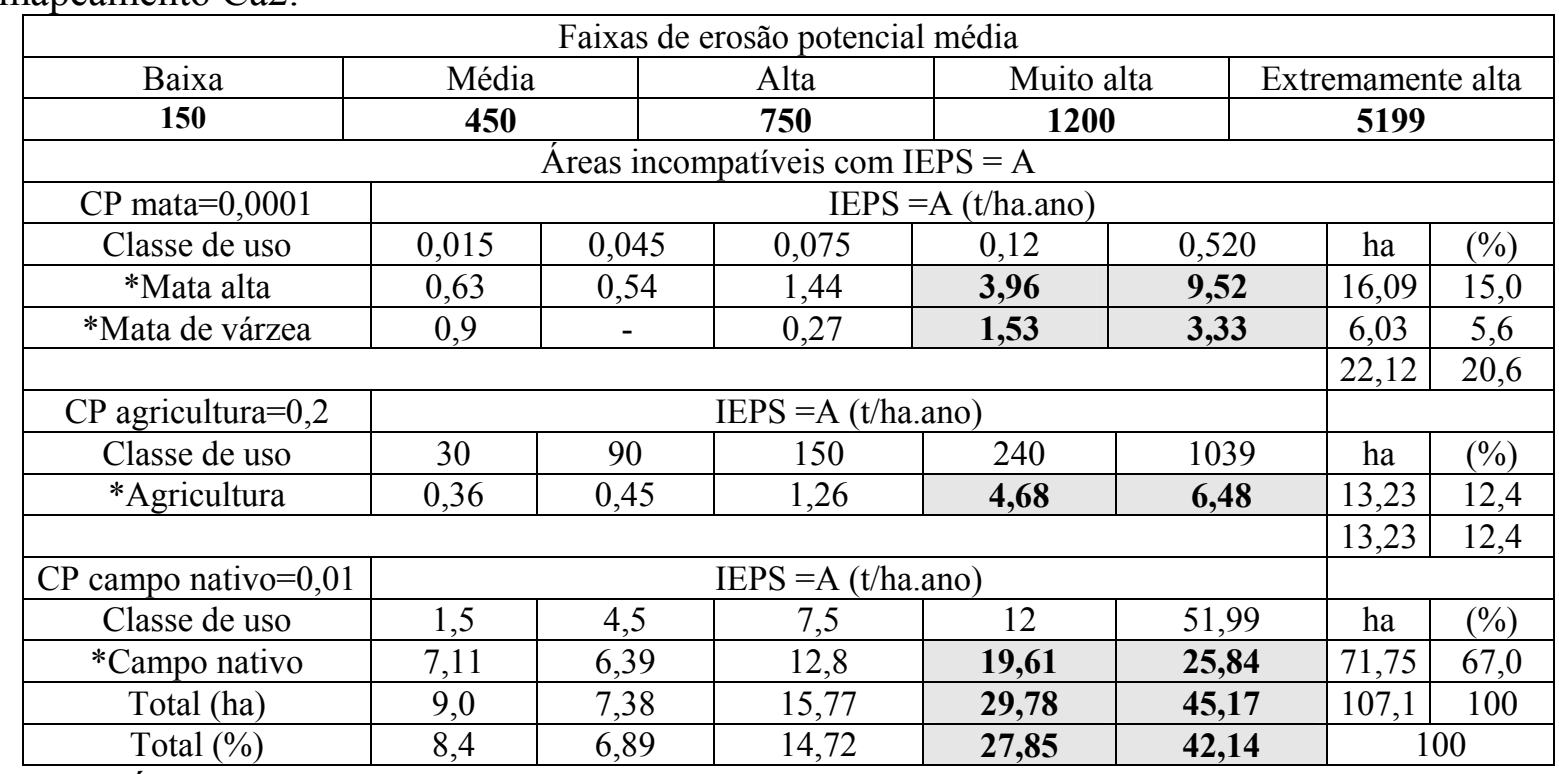

- Área em hectares

Conforme a Tabela 6, a unidade de mapeamento Lva assim como a unidade Ca2, também apresenta quatro classes de uso, com uma concentração maior de áreas nas faixas de estimativa de EP muito alta, extremamente alta, totalizando um percentual de $56,6 \%$. O uso 


\section{GEOAMBIENTE ON-LINE}

Revista Eletrônica do Curso de Geografia do Campus Jataí - UFG www.jatai.ufg.br/geo/geoambiente

| Jataí-GO | n.7 | jul-dez/2006 |

do solo predominante é o campo nativo com 52,81\%, seguido pelas classes mata alta e de várzea com $26,73 \%$ e agricultura $20,46 \%$. Esta unidade enquadra-se na aptidão agrícola 2 "(b)c, prestando-se para uso com lavouras. Insere-se na classe agricultura que apresentam áreas consideradas críticas, onde IEPS $>12,8$ t/ha.ano na maioria da área desta classe Tabela 11. Pode-se ainda observar uma amplitude de área compatível com IEPS (A) da classe de uso campo até a faixa de EP média 1200t/ha.ano, considerada muito alta.

Tabela 6 - Distribuição do uso atual do solo por faixas de erosão potencial da unidade de mapeamento Lva.

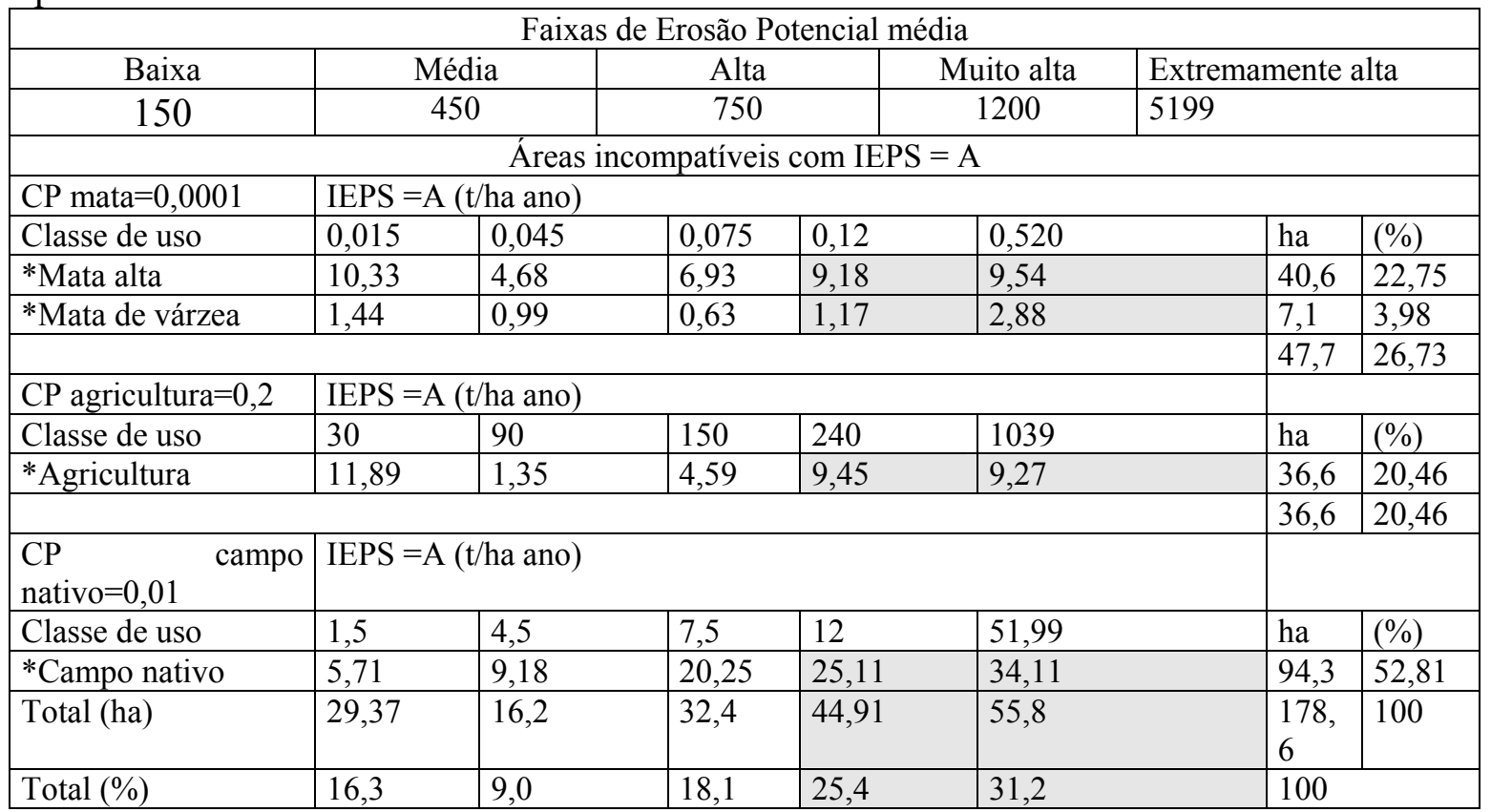

- Área em hectare

No tocante a unidade de solo Pva1, cuja distribuição geográfica na paisagem ocorre no terço inferior das elevações e nas partes baixas, mostra que há predomínio de 53,3\% de uso da área na faixa de estimativa de EP média extremamente alta Tabela 7, onde ocorrem usos de matas, agricultura e campo nativo. A aptidão agrícola para esta unidade de mapeamento $2 " \mathrm{~b}$ (c), regular para lavouras com dois cultivos ao ano, acentuando-se as perdas de solos.

Tabela 7 - Distribuição do uso atual do solo por faixas de erosão potencial da unidade de mapeamento Pva1.

\begin{tabular}{|c|c|c|c|c|}
\hline \multicolumn{5}{|c|}{ Faixas de Erosão Potencial média } \\
\hline Baixa & Média & Alta & Muito alta & Extremamente alta \\
\hline 150 & 450 & 750 & 1200 & 5199 \\
\hline \multicolumn{5}{|c|}{ Áreas incompatíveis com IEPS $=\mathrm{A}$} \\
\hline CP mata $=0,0001$ & \multicolumn{4}{|c|}{ IEPS $=\mathrm{A}(\mathrm{t} / \mathrm{ha}$ ano $)$} \\
\hline Classe de uso & \begin{tabular}{l|l}
0,015 & 0,045 \\
\end{tabular} & 0,075 & 0,520 & $(\%)$ \\
\hline
\end{tabular}




\section{GEOAMBIENTE ON-LINE}

Revista Eletrônica do Curso de Geografia do Campus Jataí - UFG www.jatai.ufg.br/geo/geoambiente

| Jataí-GO | n.7 | jul-dez/2006 |

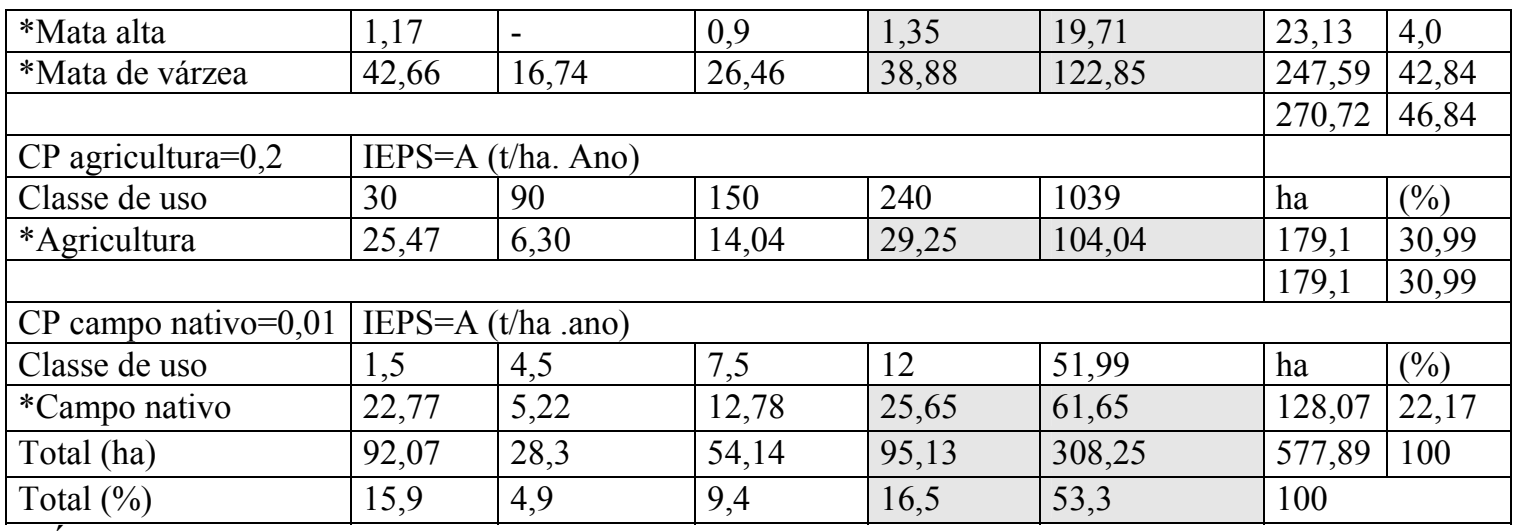

* Área em hectare

Pelos valores apresentados na Tabela 8, observa-se que a unidade de mapeamento (Pva2) carrega uma concentração de área em percentual 82,2\% das classes de uso na faixa de estimativa de erosão potencial muito alta e extremamente alta, com predominância da classe de uso campo nativo com $43,54 \%$, seguido pela agricultura com $34,78 \%$. Vinculando-se o uso nestas faixas de estimativa de EP média, a referida unidade de mapeamento recebe a classificação $4 p$ para aptidão agrícola.

Tabela 8 - Distribuição do uso atual do solo por faixas de erosão potencial da unidade de mapeamento Pva2.

\begin{tabular}{|c|c|c|c|c|c|c|c|}
\hline \multicolumn{8}{|c|}{ Faixas de Erosão Potencial média } \\
\hline Baixa & \multicolumn{2}{|l|}{ Média } & \multirow{2}{*}{\begin{tabular}{|l|} 
Alta \\
750 \\
\end{tabular}} & \multicolumn{2}{|c|}{\begin{tabular}{l|l} 
& Muito Alta \\
\end{tabular}} & \multicolumn{2}{|c|}{ Extremamente alta } \\
\hline 150 & \multicolumn{2}{|l|}{450} & & \multicolumn{2}{|c|}{1200} & \multicolumn{2}{|c|}{5199} \\
\hline \multicolumn{8}{|c|}{ Áreas incompatíveis com IEPS = A } \\
\hline CP mata $=0,0001$ & \multicolumn{7}{|c|}{ IEPS $=\mathrm{A}(\mathrm{t} / \mathrm{ha}$ ano $)$} \\
\hline Classe de uso & 0,015 & 0,045 & 0,075 & 0,12 & 0,520 & ha & $(\%)$ \\
\hline *Mata alta & 1,89 & 0,45 & 2,25 & 3,69 & 33,39 & 41,67 & 5,93 \\
\hline *Mata de várzea & 13,68 & 3,15 & 7,02 & 9,54 & 77,31 & 110,70 & 15,75 \\
\hline \multirow{2}{*}{\multicolumn{6}{|c|}{\begin{tabular}{l|l}
\multicolumn{2}{|l|}{} \\
$\mathrm{CP}$ agricultura $=0,2$ & IEPS $=\mathrm{A}(\mathrm{t} / \mathrm{ha}$. Ano $)$
\end{tabular}}} & \multirow{2}{*}{\multicolumn{2}{|c|}{\begin{tabular}{|l|l|}
152,37 & 21,68 \\
\end{tabular}}} \\
\hline & & & & & & & \\
\hline Classe de uso & 30 & 90 & 150 & 240 & 1039 & ha & $(\%)$ \\
\hline \multirow[t]{2}{*}{ *Agricultura } & 17,91 & 5,85 & 19,53 & 31,14 & 170,01 & 244,44 & 34,78 \\
\hline & & & & & & 244,44 & 34,78 \\
\hline $\begin{array}{ll}\mathrm{CP} & \text { campo } \\
\text { nativo }=0,01\end{array}$ & \multicolumn{5}{|c|}{ IEPS $=$ A (t/ha. ano $)$} & \\
\hline Classe de uso & 1,5 & 4,5 & 7,5 & 12 & 51,99 & ha & $(\%)$ \\
\hline *Campo nativo & 25,29 & 6,93 & 20,79 & 36,09 & 216,99 & 306,09 & 43,54 \\
\hline Total (ha) & 58,77 & 16,38 & 49,59 & 80,46 & 497,7 & 702,9 & 100 \\
\hline Total (\%) & 8,4 & 2,3 & 7,1 & 11,4 & 70,8 & 100 & \\
\hline
\end{tabular}

* Área em hectare

Os dados da Tabela 9 referente à unidade de mapeamento Pva3, cujas classes de uso estão concentradas na faixa de estimativa de erosão potencial extremamente alta, abrangendo $78,3 \%$ da área total, sendo que a classe campo nativo ocupa a maior extensão com percentual 


\section{GEOAMBIENTE ON-LINE}

Revista Eletrônica do Curso de Geografia do Campus Jataí - UFG www.jatai.ufg.br/geo/geoambiente

| Jataí-GO | n.7 | jul-dez/2006 |

de $51,01 \%$, seguido da agricultura 47,14\% . Está unidade de solo enquadra-se na aptidão agrícola $2 b c$, indicada para uso com lavouras. Salienta-se que a classe uso agricultura, apresenta incompatibilidade de uso, pois a utilização do solo com agricultura, esta em áreas mais suscetíveis à erosão com IEPS>7,6t/ha.ano (Tabela 14).

Tabela 9. Distribuição do uso atual do solo por faixas de erosão potencial da unidade de mapeamento Pav3.

\begin{tabular}{|c|c|c|c|c|c|c|c|}
\hline \multicolumn{8}{|c|}{ Faixa de Erosão Potencial média } \\
\hline Baixa & \multicolumn{2}{|l|}{ Média } & \multicolumn{2}{|c|}{\begin{tabular}{l|l} 
Alta &
\end{tabular}} & Muito alta & \multicolumn{2}{|c|}{ Extremamente alta } \\
\hline 150 & \multicolumn{2}{|l|}{450} & 750 & & 1200 & \multicolumn{2}{|c|}{5199} \\
\hline \multicolumn{8}{|c|}{ Áreas incompatíveis com IEPS $=\mathrm{A}$} \\
\hline CP mata $=0,0001$ & \multicolumn{7}{|c|}{ IEPS=A (t/ha ano) } \\
\hline Classe de uso & 0,015 & 0,045 & 0,075 & 0,12 & 0,520 & ha & $(\%)$ \\
\hline \multirow[t]{2}{*}{ Mata alta } & 0,09 & - & - & - & 0,9 & 0,99 & 1,85 \\
\hline & & & & & & 0,99 & 1,85 \\
\hline $\mathrm{CP}$ agricultura $=0,2$ & \multicolumn{5}{|c|}{ IEPS=A (t/ha. Ano) } & & \\
\hline Classe de uso & 30 & 90 & 150 & \multicolumn{2}{|r|}{1039} & ha & $(\%)$ \\
\hline \multirow[t]{2}{*}{ Agricultura } & 4,5 & 0,36 & 2,25 & 2,07 & 16,02 & 25,2 & 47,14 \\
\hline & & & & & & 25,2 & 47,14 \\
\hline $\begin{array}{ll}\mathrm{CP} & \text { campo } \\
\text { nativo }=0,01 & \end{array}$ & \multicolumn{5}{|c|}{$\mathrm{IEPS}=\mathrm{A}(\mathrm{t} / \mathrm{ha} \cdot \mathrm{ano})$} & & \\
\hline Classe de uso & 1,5 & 4,5 & 7,5 & 12 & 51,99 & ha & $(\%)$ \\
\hline Campo nativo & 3,15 & - & 1,08 & 1,35 & 21,69 & 27,27 & 51,01 \\
\hline Total (ha) & 7,7 & & 3,3 & 3,4 & 38,6 & 53,46 & 100 \\
\hline Total (\%) & 14,4 & 0,7 & 6,2 & 6,4 & 72,3 & 100 & \\
\hline
\end{tabular}

Os resultados de adequação agrícola para cada unidade de mapeamento, foram obtidas contrastando-se os resultados do índice de estimativa de perdas de solos (A) para diversos fatores de CPgenéricos (Tabela 1) e LSmédios versus a indicação sugerida pelo Sistema FAO/brasileiro e graus de limitação por suscetibilidade a erosão. Desta forma foi possível visualizar a distribuição das perdas por relação LS e estabelecer limites nas unidades de mapeamento, quanto ao índice de tolerância de perdas de solos (IT) para diversos CP. Nas células sombreadas (Tabelas 10 a 14), destacam-se as estimativas de perdas (A) superiores ao índice de tolerância de perda, isto é, valores incompatíveis com o tipo de uso para cada unidade de mapeamento.

Tabela 10. Adequação de uso da unidade Ca2 para diversos fatores de CP.

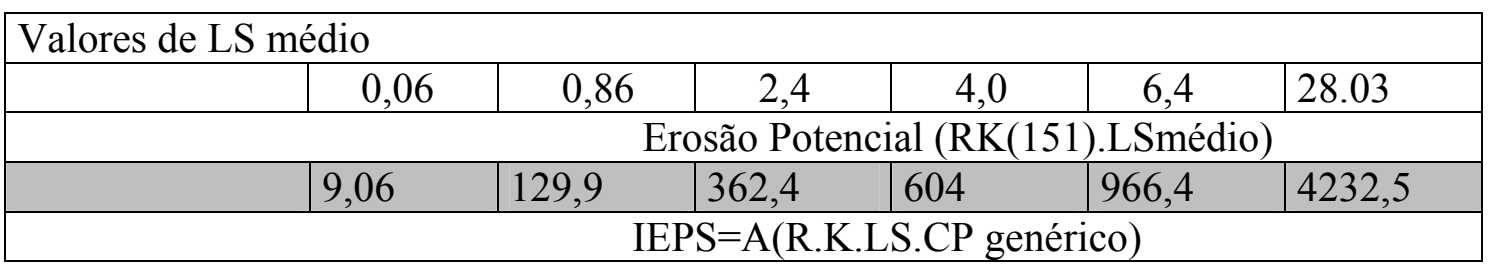




\begin{tabular}{|l|l|l|l|l|l|l|}
\hline Reflorestamento & 0,0009 & 0,012 & 0,036 & 0,060 & 0,097 & 0,423 \\
\hline Agricultura & 1,81 & 25,98 & 72,48 & 120,8 & 193,28 & 846,5 \\
\hline Campo & 0,091 & 1,299 & 3,62 & 6,04 & 9,66 & 42,32 \\
\hline Pastagem & 0,91 & 12,99 & 36,24 & 60,4 & 96,64 & 423,3 \\
\hline Floresta & 0,0004 & 0,005 & 0,014 & 0,024 & 0,039 & 0,169 \\
\hline
\end{tabular}

Notas: aptidão agrícola: $3(b)$; valor de R.K $=151$ t.ha $^{-1} \cdot$ ano $^{-1}$; valor de IT $=7,5$ t.ha $^{-1} \cdot$ ano $^{-1}$

Tabela 11. Adequação de uso da unidade Lva para diversos fatores de CP.

\begin{tabular}{|l|l|l|l|l|l|l|}
\hline \multicolumn{7}{|c|}{ Valores de LS médio } \\
\hline & 0,06 & 0,86 & 2,4 & 4,0 & 6,4 & 22,03 \\
\hline & 7,4 & 106,6 & 297,6 & 496 & 793,6 & 2731,7 \\
\hline & \multicolumn{7}{c|}{ IEPS=A(R.K.LS.CP genérico) } \\
\hline Reflorestamento & 0,0007 & 0,011 & 0,029 & 0,049 & 0,079 & 0,273 \\
\hline Agricultura & 1,48 & 21,32 & 59,52 & 99,2 & 158,72 & 546,3 \\
\hline Campo & 0,074 & 1,07 & 2,98 & 4,96 & 7,94 & 27,32 \\
\hline Pastagem & 0,74 & 10,66 & 29,76 & 49,6 & 79,36 & 273,2 \\
\hline Floresta & 0,0003 & 0,004 & 0,012 & 0,019 & 0,032 & 0,109 \\
\hline
\end{tabular}

Notas: aptidão agrícola: $2^{\prime \prime}(b) c$; valor de R.K $=124$ t.ha ${ }^{-1} \cdot$ ano $^{-1}$; valor de IT $=12,8$ t.ha ${ }^{-1}$. ano ${ }^{-1}$

Tabela 12. Adequação de uso da unidade Pval para diversos fatores de CP.

\begin{tabular}{|c|c|c|c|c|c|c|}
\hline \multicolumn{7}{|c|}{ Valoresde LS médio } \\
\hline & 0,06 & 0,86 & 2,4 & 4,0 & 6,4 & 27,6 \\
\hline \multicolumn{7}{|c|}{ Erosão Potencial ( RK(186).LSmédio ) } \\
\hline & 11,16 & 159,9 & 446,4 & 744 & 1190 & 5133,6 \\
\hline \multicolumn{7}{|c|}{ IEPS=A(R.K.LS.CP genérico) } \\
\hline $\begin{array}{l}\text { Reflorestament } \\
\text { o }\end{array}$ & 0,001 & 0,016 & 0,045 & 0,074 & 0,012 & 0,513 \\
\hline Agricultura & 2,23 & 31,99 & 89,28 & 148,8 & 238 & 1026,7 \\
\hline Campo & 0,11 & 1,59 & 4,46 & 7,44 & 11,9 & 51,34 \\
\hline Pastagem & 1,12 & 15,99 & 44,64 & 74,4 & 119 & 513,4 \\
\hline Floresta & 0,0004 & 0,0064 & 0,0179 & 0,0298 & 0,0476 & 0,205 \\
\hline
\end{tabular}

Notas: aptidão agrícola: $2^{\prime \prime} b(c)$; valor de R.K $=186$ t.ha $^{-1} \cdot$ ano $^{-1}$; valor de IT. $=7,6$ t.ha ${ }^{-1}$.ano ${ }^{-1}$

Tabela 13. Adequação de uso da unidade Pva2 para diversos fatores de CP.

\begin{tabular}{|l|l|l|l|l|l|l|l|}
\hline \multicolumn{7}{|c|}{ Valores de LS médio } \\
\hline & 0,06 & 0,86 & 2,4 & 4,0 & 6,4 & 27,9 \\
\hline & \multicolumn{7}{c|}{ Erosão Potencial ( RK(186).LSmédio ) } \\
\hline & 11,16 & 159,9 & 446,4 & 744 & 1190 & 5189 \\
\hline Reflorestamento & 0,001 & 0,016 & 0,045 & 0,074 & 0,012 & 0,519 \\
\hline Agricultura & 2,23 & 31,99 & 89,28 & 148,8 & 238 & 1038 \\
\hline Campo & 0,11 & 1,59 & 4,46 & 7,44 & 11,9 & 51,19 \\
\hline
\end{tabular}




\begin{tabular}{|l|l|l|l|l|l|l|}
\hline Pastagem & 1,12 & 15,99 & 44,64 & 74,4 & 119 & 519 \\
\hline Floresta & 0,0004 & 0,0064 & 0,0179 & 0,0298 & 0,0476 & 0,208 \\
\hline
\end{tabular}

Tabela 14. Adequação de uso da unidade Pva3 para diversos fatores de CP.

\begin{tabular}{|c|c|c|c|c|c|c|}
\hline & \multicolumn{6}{|c|}{ Valor de LS médio } \\
\hline & 0,06 & 0,86 & 2,4 & 4,0 & 6,4 & 24,86 \\
\hline \multicolumn{7}{|c|}{ Erosão Potencial ( RK(186).LSmédio ) } \\
\hline & 11,16 & 159,9 & 446,4 & 744 & 1190 & 4623,9 \\
\hline & \multicolumn{6}{|c|}{ IEPS=A(R.K.LS.CP genérico) } \\
\hline $\begin{array}{l}\text { Reflorestament } \\
\text { o }\end{array}$ & 0,001 & 0,016 & 0,045 & 0,074 & 0,012 & 0,462 \\
\hline Agricultura & 2,23 & 31,99 & 89,28 & 148,8 & 238 & 924,8 \\
\hline Campo & 0,11 & 1,59 & 4,46 & 7,44 & 11,9 & 46,23 \\
\hline Pastagem & 1,12 & 15,99 & 44,64 & 74,4 & 119 & 462,4 \\
\hline Floresta & 0,0004 & 0,0064 & 0,0179 & 0,0298 & 0,0476 & 0,185 \\
\hline
\end{tabular}

Notas: aptidão agrícola: $2 b c$; valor de R.K $=186$ t.ha $^{-1} \cdot$ ano $^{-1}$; valor de IT $=7,6$ t.ha $^{-1} \cdot$ ano $^{-1}$

Conforme as tabela 13 e 14, os valores indicam que a unidade de mapeamento Pva2 está inserida numa faixa da relação LS médio de 0.06 a 27,9 a unidade Pva3 0.06 a 24,86 e a unidade Pva1 0.06 a 27,6. Para CP de reflorestamento e floresta nativa, não há limites de uso para estas atividades em todas as três unidades de mapeamento; por outro lado, com relação a CP de campo nativo, o valor máximo de LS médio é de 4,0 correspondendo a uma perda de solo de 7,44 t/ha.ano e para pastagem o valor de LS médio é de 0.06 equivalente a 1,12 t/ha.ano, estando de acordo com os valores propostos por BERTONI e LOMBARDI (1985), que corresponde a um valor máximo de 7,6 t/ha/ano, compatível com as aptidões agrícolas nos níveis $4 p$ para a unidade Pva2, $2 b c$ para Pva3 e 2"b(c) para Pva1.

\section{4 - Conclusões}

- Os índices de estimativa da erosão potencial restringem mais a utilização da terra para agricultura do que pela aptidão agrícola, estando está discrepância associada ao peso relativo aos fatores da erosão potencial quanto à erosividade regional da chuva ( $\mathrm{R})$, topográfico (declividade e comprimento de rampa) (LS) e fragilidade do solo à erosão $(\mathrm{K})$;

- Utilizando Erosão potencial observa que as áreas ocupadas com predominâncias das classes de uso de mata alta e mata de várzea correspondem aos menores índices de estimativas de perdas de solos, áreas de lavouras estão super-utilizadas. 
- A maior parte da região estudada encontra-se em desacordo com sua real aptidão, onde há necessidade de prosseguimento nas pesquisas e experimentação convencional e detalhamento de campo. Entretanto esses dados podem ajudar ao desenvolvimento de programas de conservação do solo e determinar ações mediante a amplitude do problema.

\section{5 - Referências Bibliográficas}

ANDERSON, J. R.; HARDY, E. E; ROACH, J.T.; WITMER, R.E. Sistema de classificação do uso da Terra e do revestimento do solo para utilização com dados de sensores remotos. Rio de Janeiro : IBGE, 1979. 80p.

BECEGATO, V.A.; MACIEL, M.M.; CABRAL, J.B.P.; MACHADO, R.V. Sistema de informação geográfica para estudo temporal do uso do solo. Revista de Ciências Agroveterinárias, Lages, v.3, n.1, p.9-19, 2004.

BERTONI, J.; LOMBARDI NETO, F.; BENATTI, R. J. Equação de perdas de solo. _Boletim Técnico do Instituto Agronômico, (21), 1975 25p.

BERTONI, J. \& LOMBARDI NETO, F. Conservação do solo. Piracicaba, Livroceres, 1985, $368 \mathrm{p}$.

CASTRO, F.C. Programas para calculo do fator $L S$ da equação universal de perdas de solo, IAPAR, Contribuição $n^{\circ} 184,6^{\circ}$ Encontro Nacional de Pesquisa Sobre Conservação de Solo. Campo Grande, 1986.

FOSTER, G.R.; WISCHMEIER, W.H. Evaluating irregular slope for soil loss prediction. Trans. ASEA 1974. 17: 305-309.

LOPES ASSAD, M.L. Uso de um sistema de informações geográficas na determinação da aptdião agrícola de terras. Revista brasileira de ciência do solo, Campinas, 19:133-139, 1995. MORAES, R.L. Contribuição à identificação de tipos de utilização da terra através de fotografias aéreas. Boletim geográfico, 27 (204):75-76, 1968.

MAACK, R. Mapa Geológico do Estado do Paraná. escala 1:750.000 Serviço de Geologia do Instituto de Biologia e Pesquisas Tecnológicas. 1953

RABBEN, E.I. Fundamentals Photointerpretation. In: American Society of Photogrametry, Manual of Photografic Interpretation Washington, 1960, cap. 3 99-136.

RAMALHO FILHO, A.; BEEK, K. J. Sistema de avaliação da aptidão agrícola das terras. 3.ed. ver. Rio de Janeiro: EMBRAPA-CNPS, 1995. 65p. 
RAY, R.G. Fotografias aéreas na interpretação e mapeamento geológico. São Paulo, Instituto Geográfico e Geológico de São Paulo, 1963, 88 p.

RICCI, M. \& PETRI, S. Princípios de aerofotogrametria e interpretação geológico. São Paulo, Nacional, 1965. 226 p.

ROCHA, J.V.; LOMBARDI NETO, F.; BACELLAR, A.A.A. Cálculo do fator comprimento de rampa (L): uma metodologia para uso em sistema de informação geográfica. In: Simpósio Nacional de Controle e de Erosão, 5., 1995, Bauru. Anais..., 1995, p.421-422.

RODRIGUES, J.B.T.; ZIMBACK, C.R.L.; PIROLLI, E.L. Utilização de sistema de informação geográfica na avaliação do uso da terra em Botucatu (SP). R. Bras. Ci. Solo, 25:675-681, 2001.

ROLOFF, G. \& DERNADIN, J. E. Estimativa simplificada da erodibilidade do solo. In X Reunião brasileira de manejo e conservação de solo e água. Pequena propriedade $\mathrm{x}$ desenvolvimento sustentado. Florianópolis, 1994. 146-153p.

RUFINO, R. L.; BISCAIA R. C. M.; MERTEN, G. H. Determinação do potencial erosivo da chuva do Estado do Paraná, através de pluviometria: terceira aproximação. Manejo e conservação do solo e da água. Revista Brasileira de Ciência do Solo. Campinas, 17(3) 439450.1993.

SILVA, G. M. Avaliação de Terras para o Desenvolvimento Rural com o Apoio do Enfoque de Sistemas, no município de Campo do Tenente-PR. Curitiba, 125p. (Mestrado Universidade Federal do Paraná).

STEIN, D.P.; DONZELLI, P.L.; GIMENEZ, A.F.; PONÇANO, W.L.; LOMBARDI NETO, F. Potencial de erosão laminar, natural e antrópica na bacia do Peixe-Paranapanema. In: Simpósio Nacional de controle de erosão, 4, Marília, 1987. Anais. São Paulo, Departamento Técnico de Águas e Energia elétrica, 1987. p. 105-135. 